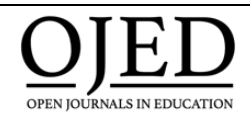

Volume 5, Issue 1 (2020), pp. 118-122

International Journal of

Multidisciplinary Perspectives in Higher Education

ISSN: 2474-2546 Print/ ISSN: 2474-2554 Online

https://ojed.org/jimphe

\title{
The COVID-19 Crisis and Faculty Members in Higher Education: From Emergency Remote Teaching to Better Teaching through Reflection
}

\author{
Charles B. Hodges \\ Georgia Southern University, U.S.A \\ Denver J. Fowler \\ Southern Connecticut State University, U.S.A
}

\begin{abstract}
This brief essay highlights how the COVID-19 crisis forced many faculty members in the higher education setting to abruptly transition from face-toface and hybrid instruction to remote teaching. We propose that incorporating systematic reflection regarding one's professional practice as a faculty member will lead to overall improved instruction regardless of future course modality and any circumstances that force modality changes.
\end{abstract}

Keywords: Emergency Remote Teaching; COVID-19; Online Instruction; Instructional Delivery; Instructional Design; Course Design; Course Modality; Course Instruction

John Dewey is credited with the quote, "We do not learn from experience... we learn from reflecting on experience." In this essay we offer a rationale and framework for reflection in higher education that instructors can apply to improve their professional practice. In particular, we note that reflection should be applied following changes to instruction due to a crisis, such as the COVID-19 pandemic, for the purposes of improving instruction following the crisis. Reflection is situated as part of standard instructional design processes. 
Like it or not, in the Spring of 2020 most higher education faculty members had to quickly move from their normal mode of instructional delivery to what Hodges et al. (2020) described as emergency remote teaching (ERT). Emergency remote teaching "is a temporary shift of instructional delivery to an alternate delivery mode due to crisis circumstances. It involves the use of fully remote teaching solutions for instruction or education that would otherwise be delivered face-to-face or as blended or hybrid courses and that will return to that format once the crisis or emergency has abated" (Hodges et al., 2020, para. 13). Peer reviewed research about this shift to ERT is only just now beginning to find its way into journals and books; however, early indications are that many faculty members struggled for one reason or another to accept ERT (i.e., Abbot, 2020; WBUR, 2020). Hill and Moore (2020) describe a four-phase progression regarding online delivery of instruction in response to COVID19. The progression begins with ERT, then to adding basics, preparing for a full term of online delivery, and finally arriving at a new normal phase with improved proficiency and ability to support online delivery. We posit that the professional practice of instructors in institutions of higher education should be enhanced following the COVID-19 ERT experience, or any similar situation, if they incorporate a process of reflection into their praxis.

\section{Better Teaching Through Reflection}

Most instructional design models describe a cyclic process of steps with the results of formative evaluation feeding back into earlier phases to inform revisions and improvements (see Branch \& Dousay, 2015 for a comprehensive review of instructional design models). Individual instructors in content areas outside of instructional design and technology may not be aware of specific instructional design models, but a design cycle with intentional evaluation informing future efforts should not be a foreign concept to most people. Many instructional deign processes can be generically described as following an ADDIE process. ADDIE is an acronym describing phases of instructional design and development consisting of analysis, design, development, implementation, and evaluation. The findings from the evaluation phase feed back into the other phases for revisions aimed at improving the learning experience under consideration. The evaluation should extend beyond the assessment of learners and should include feedback on all elements of the learning experience both for the learners and the instructors. Reflection is one way to collect evaluation information from instructors.

It is common in education to discuss the concept of reflection. Reflection is a "considered a cognitive process and as such can be generalised across professional contexts" (Marshall, 2019, p. 405). Despite the frequent use of the term the concept of reflection does not have a standard definition (Marshall, 2019; Nguyen, Fernandez, Karsenti, \& 
Charlin, 2014). For the purposes of the present paper, we will use Marshall's (2019) definition, which was the result of a synthesis of other definitions in the literature:

"Reflection is a careful examination and bringing together of ideas to create new insight through ongoing cycles of expression and re/evaluation" (p. 411).

The authors regularly use reflection in their professional practice and intentionally did so during spring 2020 semester while ERT was widespread.

The University of New South Wales offers a course through the FutureLearn platform titled Introduction to Enhancing Learning and Teaching in Higher Education. In that course (FutureLearn, n.d.) a structure for reflection is offered that we believe will assist instructors as they reflect on their ERT experiences and move forward to improve their practice with online delivery or any delivery mode for that matter:

5) What worked well?

6) What did not work well?

7) What will I do the same next time?

8) What will I do differently next time?

It is then recommended (Future Learn, n.d.) that you examine your readiness by asking the following:

9) What knowledge, skills or abilities are necessary to deliver a specific learning experience?

10) To what extent do I possess those skills?

11) What do I need to do to develop or enhance those skills?

12) How will this affect the way I present that learning experience?

13) What problems might this entail that I need to anticipate and overcome?

These questions should be answered and considered by individual instructors, but also may be shared and discussed with others depending on personal contexts and the cultures in which one works.

While it may be the first impulse to revert to your previous methods and modes of instruction once COVID-19 is behind us, one must remember that COVID-19 may end, but ERT may be needed in the future for other reasons. For example, online delivery has been used for continuity of instruction efforts following earthquake (Baytiyeh, 2018) or polar vortex (Samson, 2020). Thus, again, faculty members will want to purposely reflect on what worked well and what might need improvement. Additionally, through the process of reflection, faculty members may find that there are elements of your ERT experience that can improve your pre-COVID-19 teaching practice. Instructors at the Virginia Tech Carillon School of Medicine moved a traditional, small-group, face-to-face problem-based learning curriculum online in response to COVID-19 (Virginia Tech, 2020). The 
faculty are intentionally recording what works in that new delivery mode so that can inform their practice after the need for ERT has passed.

\section{Conclusions/ Implications}

Our hope is this Brief essay will shed light on the current educational issues and challenges (associated with the COVID-19 crisis) facing faculty members in the higher education setting. In addition, it is our hope that this essay will contribute to the extant literature on both technology and online teaching in the higher education setting. The COVID-19 pandemic forced many faculty members to quickly transition from face-to-face and hybrid forms of instruction to fully online remote teaching. Due to the suddenness of this transition, Hodges et al. (2020) have described this sudden shift as ERT. Through this essay, we challenge faculty members to reflect on this ERT experience, and through a continuous growth improvement mindset, identify what "went well" and what "did not go well" with regard to teaching normally face-to-face and hybrid courses fully online via remote teaching. We believe this asserted reflection will lead to better teaching regardless of the course modality, be it back to face-to-face, hybrid, or remote. Likewise, we argue such reflection will lead to better preparedness if such an epidemic or other emergency situation should happen in the future. Finally, with numerous universities and colleges now offering online versions of their face-to-face and hybrid program offerings, we see this reflection as key to serving as a faculty member in higher education in the $21^{\text {st }}$ century and beyond.

\section{References}

Abbot, E. (2020). Students and teachers struggle with remote education due to coronavirus. The Hill. https://tinyurl.com/y9953zos

Baytiyeh, H. (2018). Online learning during post-earthquake school closures. Disaster Prevention and Management, 27(2), 215-227. https://doi.org/10.1108/DPM-07-2017-0173

Branch, R. M., \& Dousay, T. A. (2015). Survey of instructional design models. (5th ed). Association for Educational Communications and Technology.

FutureLearn (n.d.). Reflection and evaluation. https://www.futurelearn.com/courses/enhancing-learning-andteaching $/ 0 /$ steps $/ 26451$

Hodges, C.B., Moore, S.L., Lockee, B.B., Trust, T., Bond, M.A. (2020, March 27). The difference between emergency remote teaching and online learning. EDUCAUSE Review. https://tinyurl.com/rekxcrq

Marshall, T. (2019). The concept of reflection: a systematic review and thematic synthesis across professional contexts. Reflective Practice, 20(3), 396-415. https://doi.org/10.1080/14623943.2019.1622520 
Moore, S.L., \& Hill, P. (2020). Planning for resilience, not resistance. Phil on EdTech. https://philonedtech.com/planning-for-resilience-notresistance/

Nguyen, Q. D., Fernandez, N., Karsenti, T., \& Charlin, B. (2014). What is reflection? A conceptual analysis of major definitions and a proposal of a five-component model. Medical education, 48(12), 1176-1189. https://doi.org/10.1111/medu.12583

Samson, P. (2020, March 3). The coronavirus and class broadcasts. EDUCAUSE Review. https://er.educause.edu/blogs/2020/3/thecoronavirus-and-class-broadcasts

Virginia Tech. (2020, April 10). Medical school moves its small-group, problem-based learning online to help stop the spread of COVID19. https://vtnews.vt.edu/articles/2020/04/vtcsom-virtualPBL.html

WBUR. (2020, April 20). For students and professors remote learning is no substitute for being on campus. https://www.wbur.org/edify/2020/04/20/college-campus-remotelearning-substitute

\section{Author Bios}

CHARLES B. HODGES, PhD, is a Professor in the College of Education, Georgia Southern University, Statesboro, GA (USA). His major research interests are aligned with online teaching and learning, learner motivation, and the meaningful integration of technology into teaching and learning. Email: chodges@georgiasouthern.edu

DENVER J. FOWLER, EdD, is an Associate Professor of Educational Leadership \& Policy Studies within the College of Education at Southern Connecticut State University in New Haven, CT (USA). His major research interests are PK-12 educational leadership, namely as it applies to the superintendency and principalship. Email: fowlerd3@southernct.edu 